\title{
Apparent mass of the human body in the vertical direction: inter-subject variability
}

\author{
Martin G.R. Toward, Michael J. Griffin \\ Human Factors Research Unit, Institute of Sound and Vibration Research, \\ University of Southampton, Southampton, SO17 1BJ, England
}

Correspondence address:

Professor Michael J. Griffin

Human Factors Research Unit

Institute of Sound and Vibration Research

University of Southampton

Southampton SO17 1BJ

England

Telephone: (+44) 02380592277

Facsimile: (+44) 02380592927

e-mail: M.J.Griffin@soton.ac.uk 


\begin{abstract}
The biodynamic responses of the seated human body to whole-body vibration vary considerably between people, but the reasons for the variability are not well understood. This study was designed to determine how the physical characteristics of people affect their apparent mass and whether inter-subject variability is influenced by the magnitude of vibration and the support of a seat backrest. The vertical apparent masses of 80 seated adults ( 41 males and 39 females aged 18 to 65 ) were measured at frequencies between 0.6 and $20 \mathrm{~Hz}$ with four backrest conditions (no backrest, upright rigid backrest, reclined rigid backrest, reclined foam backrest) and with three magnitudes of random vibration $\left(0.5,1.0\right.$ and $1.5 \mathrm{~ms}^{-2}$ r.m.s.). Relationships between subject physical characteristics (age, gender, weight, and anthropometry) and subject apparent mass were investigated with multiple regression models. The strongest predictor of the modulus of the vertical apparent mass at $0.6 \mathrm{~Hz}$, at resonance, and at $12 \mathrm{~Hz}$ was bodyweight, with other factors having only a marginal effect. After correction for other variables, the principal resonance frequency was most consistently associated with age and body mass index. As age increased from 18 to 65 years, the resonance frequency increased by up to 1.7 $\mathrm{Hz}$, and when the body mass index was increased from 18 to $34 \mathrm{kgm}^{-2}$ the resonance frequency decreased by up to $1.7 \mathrm{~Hz}$. These changes were greater than the $0.9-\mathrm{Hz}$ increase in resonance frequency between sitting without a backrest and sitting with a reclined rigid backrest, and greater than the $1.0-\mathrm{Hz}$ reduction in resonance frequency when the magnitude of vibration increased from 0.5 to $1.5 \mathrm{~ms}^{-2}$ r.m.s. It is concluded that the effects of age, body mass index, posture, vibration magnitude, and weight should be taken into account when defining the vertical apparent mass of the seated human body.
\end{abstract}

Author Keywords: apparent mass; biodynamics; seats; whole-body vibration; inter-subject variability; posture; backrest; age; weight; gender. 


\section{Introduction}

The biodynamic responses of the human body influence the vibration transmitted through the seats of vehicles to drivers and passengers [1]. The biodynamic responses have been measured in various experiments and some of the findings have been used to derive idealized mechanical and mathematical models of the human body (e.g. ISO 5982 [2]). Such models might be used to measure or predict the vibration transmitted to the interface between the human body and the supporting seat surface.

Experimental studies have shown a large variability in the apparent mass of the human body and some studies have suggested reasons for some of the differences. The effect of subject characteristics on the vertical apparent mass of the body has been reported for 60 subjects (24 men, 24 women, and 12 children) sitting upright on a rigid flat seat with no backrest contact and with lower legs vertical [3]. There was a large variation in apparent mass between subjects at low frequencies, but after normalisation (dividing the modulus of the apparent mass by the static mass supported by the seat) the variability was much reduced. Most subjects had a principal resonance near $5 \mathrm{~Hz}$, with the apparent mass at this frequency about $40 \%$ greater than the static mass. It was found that the weight of subjects supported on the seat divided by their sitting height was correlated with their resonance frequency, their age was correlated with their normalised apparent mass at $20 \mathrm{~Hz}$, and their total body weight was correlated with their normalised apparent mass at their resonance frequency. There was no statistically significant effect of subject weight on resonance frequency, in contrast to other studies that have claimed the resonance frequency decreases with increasing subject mass (e.g. $[4,5])$.

Variable effects of gender on the apparent mass the body have been reported. Fairley and Griffin [3] observed that the mean normalised apparent masses of men, women, and children were similar. Wang et al. [6] suggested females have a greater normalised apparent mass than men at frequencies between 15 and $40 \mathrm{~Hz}$, Lundström et al. [7] suggested females have a slightly lower resonance frequency, and Holmlund et al. [8] claimed that females have a less distinct peak in their mechanical impedance than males. Although the effects of subject weight were controlled in these studies, either by normalising the apparent mass or by comparing 
groups with matched weights, the effects of other characteristics were not controlled, allowing the possibility that apparent effects of gender may have been confounded by the effects of other variables.

When the back is partially supported by a backrest, there is an increase in the resonance frequency of the vertical apparent mass measured at the seat surface [9] and an increase in the apparent mass at frequencies greater than the resonance frequency $[6,9]$. The resonance frequency increases when a rigid backrest is reclined $[4,9]$ but decreases when a foam backrest is reclined [9].

The resonance frequency in the vertical apparent mass of the body reduces as the magnitude of the vibration excitation increases. This non-linearity has been observed when sitting with nobackrest (e.g. [3],[8]), when sitting with a reclined backrest [4], when standing [10], and when supine [11]. It has been reported that the influence of vibration magnitude on the resonance frequency is less when sitting in a car driving posture than when sitting with no backrest support [12]. Inter-subject variability in apparent mass has been reported to be greatest at low magnitudes of vibration, with most variability when supported by a backrest or leaning forward with no backrest, and least variability when sitting upright, either with no backrest or supported by a foam backrest [13].

Ranges of 'idealized values' of vertical apparent mass of the human body are presented in ISO 5982 [2]. The values were compiled from measurements in conditions assumed to be broadly comparable. Reference values are offered for three groups of body weight $(55,75,90 \mathrm{~kg})$, with other physical characteristics (e.g. age, gender and stature) not considered. The reference values were derived from either the apparent mass or the mechanical impedance of subjects measured while sitting without the support of a backrest and while exposed to vibration at magnitudes up to $5 \mathrm{~ms}^{-2}$ r.m.s. The applicability of the idealised values provided in ISO 5982 to the drivers and passengers of common vehicles is unknown.

This study was designed to determine the relative strengths of any associations between subject characteristics (gender, age, weight, and anthropometric measurements) and the characteristics of the vertical apparent mass of the human body (especially the resonance 
frequency and the modulus of the apparent mass at $0.6 \mathrm{~Hz}$, at resonance, and at $12 \mathrm{~Hz}$ ) when seated with and without a backrest.

\section{Methods and procedures}

\subsection{Apparatus}

Vertical vibration was produced using a 1-metre stroke electro-hydraulic vibrator in the laboratories of the Human Factors Research Unit at the Institute of Sound and Vibration Research. Subjects sat on the flat upper surface of a force plate ( $0.6 \mathrm{~m}$ wide by $0.4 \mathrm{~m}$ deep) secured to a rigid seat with a rigid flat backrest having adjustable inclination. The upper surface of the force plate (Kistler $9281 \mathrm{~B}$; Kistler, Hook, UK) was $0.34 \mathrm{~m}$ above the vibrator platform on which the feet were supported. The feet of each subject were moved forward on the vibrator platform until the thighs were just touching the leading edge of the seat. The signal from the force plate was amplified using a Kistler 5007 charge amplifier. The acceleration of the platform was monitored using an HVLab SIT-pad containing a piezo-resistive accelerometer (Entran EGCSY-240D-10; Entran, Potterspury, UK).

\subsection{Vibration}

Gaussian random vibration (band-limited using 8-pole Butterworth filters between 0.125 and 25 $\mathrm{Hz}$ ) with approximately flat constant bandwidth acceleration spectra were generated and analysed using an HVLab data acquisition and analysis system (version 3.81; University of Southampton, UK). Different random signals were generated for each subject. The measured force and acceleration were acquired at 400 samples per second via $167 \mathrm{~Hz}$ anti-aliasing filters.

\subsection{Conditions}

The apparent mass of each subject was measured with four backrest conditions:

(i) sitting upright with no backrest;

(ii) sitting upright with a rigid backrest;

(iii) sitting with a rigid backrest reclined to $15^{\circ}$;

(iv) sitting with a foam backrest reclined to $15^{\circ}$. 
The apparent mass was measured at three magnitudes of vibration $\left(0.5,1.0\right.$, and $1.5 \mathrm{~ms}^{-2}$ r.m.s.) in conditions (i) and (iii), and at only one magnitude (1.0 $\mathrm{ms}^{-2}$ r.m.s.) in conditions (ii) and (iv). Each exposure to vibration was $60 \mathrm{~s}$ in duration.

The foam squab attached to the backrest in condition (iv) had a uniform thickness of $100 \mathrm{~mm}$. A spacer was placed behind the rigid backrest in conditions (ii) and (iii) so that the length of thigh contact with the seat was similar to that in the other two postures. Using a SIT-bar shaped indenter with a $100-\mathrm{N}$ preload, the $100-\mathrm{mm}$ foam was measured to have a stiffness of approximately $21 \mathrm{kN} / \mathrm{m}$ and damping of approximately $109 \mathrm{Ns} / \mathrm{m}$ at frequencies between 2 and $20 \mathrm{~Hz}$.

\subsection{Subjects}

The group of 80 adult subjects participating in the experiment was chosen to be representative of the UK car driving population (Table $1 ;[14,15])$. The subjects were exposed to all conditions in a single session lasting approximately 60 minutes. For each subject the order of presentation of conditions was randomized. Subjects wore a loose fitting lap belt and had access to an emergency stop button. Subjects gave informed consent to participate in the experiment that was approved by the Human Experimentation, Safety and Ethics Committee of the Institute of Sound and Vibration Research at the University of Southampton.

\section{TABLE 1 AROUND HERE}

\subsection{Analysis}

Transfer functions were calculated between the vertical seat acceleration and the vertical force at the seat surface, to give the apparent masses of the subjects. Apparent mass was calculated using the cross-spectral density (CSD) technique with a frequency resolution of $0.195 \mathrm{~Hz}$. The apparent mass was calculated from the ratio of the cross-spectral density between the force and acceleration at the seat, to the power spectral density of the acceleration at the seat.

Prior to the calculation of the apparent mass, mass cancellation of the mass of the top platform of the force-plate $(33.0 \mathrm{~kg}$ ) was performed in the time domain to remove its influence from the measured force: the acceleration time-history on the seat surface was multiplied by the mass of 
the force platform and subtracted from the measured force. The coherency between the force and acceleration was calculated after mass cancellation and found to be greater than 0.9 over the frequency range 0.20 to $30 \mathrm{~Hz}$. At frequencies greater than $30 \mathrm{~Hz}$ the coherency tended to decrease but was generally greater than 0.8 .

The apparent mass at the primary resonance frequency was assumed to be the greatest apparent mass over the measurement range $(0.6$ to $20 \mathrm{~Hz})$. The primary resonance frequency was defined as the frequency at which the apparent mass was greatest.

\subsection{Statistical analysis}

Parametric statistics were used throughout the analysis. The paired samples $t$-test was used to compare features of the apparent mass between conditions (i.e. between backrests and magnitudes). The independent samples $t$-test was used to compare features of the apparent mass between subjects grouped by their characteristics (i.e. size, age, gender). The standard deviation was used to quantify variability in features of the apparent mass. Variability in apparent mass between conditions was tested using Levene's test of equality of variance.

Linear regression was used to identify predictors of the apparent mass. Initially, the associations between each characteristic of the subjects and the features of the apparent mass were separately analysed by ordinary least squares regression. Then, for each test condition (i.e. for each combination of backrest and vibration magnitude) significant predictors drawn from the physical characteristics were selected for the final regression model using the PASW stepwise procedure (PASW statistics, version 17.0). A significance level of 0.05 was used to enter and retain a variable in the model. Variables significantly associated with each dynamic characteristic for any test condition, together with age and gender, were then entered simultaneously into regression models. Quadratic terms of each of the significant variables were added in turn to the final regression models; in all instances F-tests showed that assuming a linear effect did not compromise goodness of fit $(p>0.1)$. Differences in the regression coefficients, $B$, between pairs of conditions (e.g. c1, c2) were tested using the null hypothesis Ho: $B_{\mathrm{c} 1}=B_{\mathrm{c} 2}$. For each independent variable in the model, $x$, first a dummy variable, $z$, was created coded 1 for $\mathrm{c} 1$ and 0 for $\mathrm{c} 2$, as well as a variable $z x$ that was the product of $z$ and the 
independent variable. Variables $x, z$, and $z x$ were then used as predictors in the regression equation. The interaction term, $z x$, tested the null hypothesis $\mathrm{Ho}_{\mathrm{c}} B_{\mathrm{c} 1}=B_{\mathrm{c} 2}$, significance $(p<0.05)$, indicating that the regression coefficient $B_{\mathrm{c} 1}$ was significantly different from $B_{\mathrm{c} 2}$.

Beta coefficients were calculated by multiplying each of the regression coefficients $(B)$ in the multiple regression models by its standard deviation and dividing by the standard deviation of the dependent variable. Thus, a change of 1.0 standard deviations in the predictor variable results in a change of 1.0 standard deviations in the criterion variable.

\subsection{Results}

\subsection{Inter subject variability}

When subjects sat upright with no backrest, the frequency of the main resonance in the 80 subjects varied between $3.5 \mathrm{~Hz}$ and $6.4 \mathrm{~Hz}$, with the mean resonance frequency around $4.9 \mathrm{~Hz}$ (Figure 1 and Table 2). At very low frequencies, the apparent mass tends toward the static mass supported on the platform, so inter-subject variability in the modulus of the apparent mass at low frequencies was reduced by normalisation (i.e. dividing the apparent mass of each subject by their static mass supported on the seat, assumed to be the apparent mass measured at $0.6 \mathrm{~Hz}$ ) (Figure 1). To test for the effects of normalisation, the apparent mass of each subject at resonance and at $12 \mathrm{~Hz}$ was rationalized (divided by the mean response of the subject group at these frequencies), for both the measured apparent mass and the normalized apparent mass. At resonance, the rationalized standard deviation was significantly reduced by normalisation (from 0.255 to $0.105 ; p<0.001$, Levene), but at $12 \mathrm{~Hz}$ the standard deviation was not significantly reduced by normalisation (from 0.236 to $0.217 ; p=0.534$ ).

\section{FIGURE 1 AND TABLE 2 AROUND HERE}

\subsection{Effects of backrest}

The mean resonance frequency increased from $4.9 \mathrm{~Hz}$ to $5.2 \mathrm{~Hz}$ when subjects made contact with an upright rigid backrest $(p<0.001)$, with a decrease in the apparent mass at resonance $(p<0.001)$ and at $0.6 \mathrm{~Hz}(p<0.001)$ (Table 2). When this rigid backrest was reclined, the resonance frequency increased further to $5.9 \mathrm{~Hz}(p<0.001)$, and the apparent mass at 
frequencies less than the resonance frequency decreased $(p<0.001$ at $0.6 \mathrm{~Hz})$. The mean resonance frequency with the reclined foam backrest was not significantly different from the resonance frequency without a backrest $(p=0.762)$, but the apparent mass at resonance and at $0.6 \mathrm{~Hz}$ was lower $(p<0.001)$.

The means and standard deviations of the apparent mass with each backrest condition are shown in Figure 2 and Table 2. Inter-subject variability in the resonance frequencies, the apparent masses at resonance, at $0.6 \mathrm{~Hz}$, and at $12 \mathrm{~Hz}$ was compared between the backrest conditions. No significant differences in inter-subject variability were found in the apparent mass at resonance, at $0.6 \mathrm{~Hz}$, or at $12 \mathrm{~Hz}$ between the four postures (in all cases $p>0.39$ ). There was greater variability in the resonance frequencies with the reclined rigid backrest than without a backrest $(p=0.004)$ and with the reclined foam backrest $(p=0.010)$.

\section{FIGURE 2 AROUND HERE}

\subsection{Effects of magnitude}

When there was no backrest, the mean resonance frequency decreased by $0.5 \mathrm{~Hz}$ (from 5.2 to $4.7 \mathrm{~Hz})$ as the vibration magnitude increased from 0.5 to $1.5 \mathrm{~ms}^{-2}$ r.m.s. $(p<0.001$; Table 2). With the rigid reclined backrest, the mean resonance frequency decreased by $1.0 \mathrm{~Hz}$ (6.4 to 5.4 $\mathrm{Hz}$ ) as the vibration magnitude increased from 0.5 to $1.5 \mathrm{~ms}^{-2}$ r.m.s. $(p<0.001)$.

At each vibration magnitude, the variability between the resonance frequencies of subjects was less without the backrest than with the reclined rigid backrest (in all cases $p<0.01$ ). Without a backrest, and with the rigid reclined backrest, the vibration magnitude did not affect the intersubject variability in resonance frequency $(p>0.1)$ (Figure 3$)$. The variability in the apparent mass at resonance, at $0.6 \mathrm{~Hz}$, and at $12 \mathrm{~Hz}$ was also not significantly affected by the vibration magnitude $(p>0.3)$

\section{FIGURE 3 AROUND HERE.}

\subsection{Effects of subject physical characteristics}

The 80 subjects were divided into various series of four equal groups according to subject weight, age, stature, and BMI, and the two genders. The means and standard deviations of the 
resonance frequency and the apparent mass at resonance, at $0.6 \mathrm{~Hz}$, and at $12 \mathrm{~Hz}$ were calculated for each group (Table 3).

\section{TABLE 3 AROUND HERE}

Without the backrest, at both the resonance frequency and at $12 \mathrm{~Hz}$ there were significant differences in the apparent mass between all pairings of weight groups $(p<0.01)$. However, after normalisation, there were no significant differences between the normalised apparent masses at resonance for the three lightest weight groups $(p>0.08)$, although the mean normalised apparent mass at resonance of the heaviest group was significantly greater than that of each of these three lighter groups $(p<0.028)$ (Figure 4). The only significant pairings at $12 \mathrm{~Hz}$ were between Groups 1 and $3(p=0.039)$, and between Groups 2 and $3(p=0.024)$. There were no significant differences between weight groups in the phase response at $5 \mathrm{~Hz}$ or $12 \mathrm{~Hz}(p>0.2)$.

\section{FIGURE 4 AROUND HERE}

Relative to the large and systematic effects of subject mass, the effects of age, gender, stature, and BMI on the apparent masses of the subject groups were small (Table 3). Stature, gender and BMI were highly correlated with body weight ( $p<0.001$, Pearson correlation) but age was not $(p=0.21)$. Some of the apparent variability in Table 3 may be associated with variations in subject mass within the stature, BMI, and gender groups. However, the normalised apparent masses show only small differences in apparent mass associated with age, stature, BMI, and gender (Figure 5).

\section{FIGURE 5 AROUND HERE}

\subsection{Bivariate regression analysis}

Bivariate regression analysis for the condition with no backrest (Table 4) showed that an increase in age of 10 years was associated with an increase of $0.27 \mathrm{~Hz}$ in the resonance frequency (Table 4; regression coefficient, $B=0.027 \mathrm{~Hz}_{\text {.year }}{ }^{-1} ; p<0.001$ ). The effect of age on resonance frequency was similar without the backrest and with the reclined rigid backrest (Figure 6; $B=0.022 \mathrm{~Hz}$.year ${ }^{-1}, p=0.007$ ). Age had a positive association with the apparent mass at $12 \mathrm{~Hz}(p<0.001)$, but not with the apparent mass at resonance or at $0.6 \mathrm{~Hz}(p>0.05)$. 


\section{TABLE 4 AROUND HERE}

All of the physical measures (weight - see Figure 7, stature, BMI, knee height, buttock-knee length, sitting height) had positive associations with the apparent mass at resonance, at $0.6 \mathrm{~Hz}$, and at $12 \mathrm{~Hz}$. There was a negative association between the resonance frequency and BMI with the reclined rigid backrest $\left(B=0.066 \mathrm{~Hz} \cdot \mathrm{m}^{2} \cdot \mathrm{kg}^{-1}, p=0.009\right)$ but not without the backrest $(p=0.843)$. Scatter plots suggest greater inter-subject variability in the relation between resonance frequency and both age and BMI with the reclined rigid backrest than with no backrest (Figure 6).

\section{FIGURE 6 AND 7 AROUND HERE}

\subsection{Multiple regression analysis}

Multiple regression models investigated how the characteristics of the apparent mass depended on subject characteristics with each backrest condition at an excitation magnitude of $1.0 \mathrm{~ms}^{-2}$ r.m.s. (Table 5). Having adjusted for the effect of other predictors, age was positively associated with the resonance frequency in all backrest conditions $(p<0.001)$, with the effect greatest when seated with the reclined foam backrest $(B=0.36 \mathrm{~Hz}$ per 10 years). No significant differences in the association of age with resonance frequency were found between pairs of backrest conditions (in all cases, $p>0.118$ ). Body mass index had an inverse association with resonance frequency in the three conditions with a backrest $(p<0.093)$. The association of BMI with resonance frequency was stronger with the reclined rigid backrest $\left(B=-0.088 \mathrm{~Hz}\right.$ per kgm$\left.{ }^{-2}\right)$ than without a backrest $\left(B=-0.026 \mathrm{~Hz}\right.$ per $\left.\mathrm{kgm}^{-2}\right)$ or with a reclined foam backrest $(B=-0.035 \mathrm{~Hz}$ per $\left.\mathrm{kgm}^{-2}\right)(p=0.017, p=0.037$ respectively). Log transformations of BMI and age were used to explore and correct any effects of skews in their distributions. Regression analyses using, initially, age, gender and BMI, and subsequently log(age), gender, and $\log (\mathrm{BMI})$, as predictors of resonance frequency were found to produce almost identical results in terms of the statistical strength of associations. However, by retaining the age and BMI variables in their original units the interpretation of the results is made easier. The apparent mass at resonance, at $0.6 \mathrm{~Hz}$, and at $12 \mathrm{~Hz}$ was strongly associated with subject weight, with apparent mass increasing at a rate greater than the increase in subject weight at resonance $(B=1.35$ to 1.58$)$, slightly less than 
subject weight at $0.6 \mathrm{~Hz}(B=0.74$ to 0.87$)$, and much less than subject weight at $12 \mathrm{~Hz}(B=0.27$ to 0.35$)(p<0.001)$. The apparent mass at $12 \mathrm{~Hz}$ was positively associated with age without the backrest, and with the upright foam and reclined foam backrests, but not with the reclined rigid backrest. After adjusting for age and body mass index, males had higher resonance frequencies than females with the reclined rigid backrest at $1.0 \mathrm{~ms}^{-2}$ r.m.s $(B=0.57 \mathrm{~Hz}, p<0.001$, Table 5) and $1.5 \mathrm{~ms}^{-2}$ r.m.s $(B=0.38 \mathrm{~Hz}, p<0.05$, Table 6). With the reclined rigid backrest, the apparent mass was greater for males than females at $0.6 \mathrm{~Hz}$ and at $12 \mathrm{~Hz}$ ( $p=0.047, p=0.042$, respectively). For each backrest condition, the $R^{2}$ values indicate that the models accounted for more of the variability in the modulus of the apparent mass than the variability in the resonance frequency.

\section{TABLE 5 AND 6 AROUND HERE}

In contrast to the strong effect of weight on the measured apparent mass at resonance, weight was not significantly associated with the normalised apparent mass at resonance with any backrest condition (in all cases, $p>0.08$; see Table 7 ). The only significant associations with normalised apparent mass at resonance were gender (greater in males; $p=0.004$ ) and kneeheight (greater with increased knee height; $p=0.008$ ), both when seated with the reclined rigid backrest. When there was no backrest, the normalised apparent mass at $12 \mathrm{~Hz}$ was positively associated with age $(p=0.024)$ and greater for males $(p=0.046)$. With the reclined rigid backrest, the normalised apparent mass at $12 \mathrm{~Hz}$ was also greater for males $(p=0.01)$, and positively associated with weight $(p=0.044)$, but negatively associated with stature $(p=0.009)$ and BMI $(p=0.016)$. With the reclined foam backrest, the normalised apparent mass at $12 \mathrm{~Hz}$ was positively associated with age $(p=0.004)$. There were no associations between subject characteristics and the normalised apparent mass at $12 \mathrm{~Hz}$ when seated with the upright rigid backrest. For all backrest conditions, the $R^{2}$ values indicate that subject characteristics explain less of the variability in the normalised apparent mass at resonance and at $12 \mathrm{~Hz}$ than they explain in the apparent mass before normalisation (compare Tables 5 and 7 ).

\section{TABLE 7 AROUND HERE}

Without a backrest, and with the reclined rigid backrest, the magnitude of vibration had no significant effect on the associations between the resonance frequency and either age, gender 
or BMI (in all cases, $p>0.10$ ) (Table 6). Similarly, there was no evidence of any change in the associations between the apparent mass at $0.6 \mathrm{~Hz}$, at resonance, and at $12 \mathrm{~Hz}$ and weight, age, and gender with a change in vibration magnitude (in all cases, $p>0.49$ ). The reduction in the resonance frequency when the vibration magnitude increased from 0.5 to $1.5 \mathrm{~ms}^{-2}$ r.m.s. was calculated as a measure of the non-linearity of each subject, but there were no associations between this measure and any of the subject characteristics when there was no backrest ( $p>0.1$; stepwise multiple regression analysis). With the reclined rigid backrest, the decrease in the resonance frequency with increased magnitude of vibration was $0.27 \mathrm{~Hz}$ greater for the males than for the females $(p=0.012)$, with other characteristics having no significant effect on this measure of non-linearity $(p>0.1)$.

\section{Discussion}

\subsection{Predictors of the magnitude of the apparent mass}

Standardized regression coefficients (beta coefficients) were calculated to show the relative contribution of the significant predictors of the apparent mass with each backrest condition (Table 8). Body weight was much the strongest predictor of the apparent mass at $0.6 \mathrm{~Hz}$, at resonance, and at $12 \mathrm{~Hz}$, with other factors having only marginal effects. The stronger effect of body weight can be seen in the normalised apparent masses of the subjects when they are grouped by body weight, stature, BMI, and gender (compare Figures 4 and 5 ).

\section{TABLE 8 AROUND HERE}

\subsection{Predictors of resonance frequency}

The sitting condition influenced whether subject age, body mass index, or gender was associated with the principal resonance frequency in the apparent mass. In all postures, the resonance frequency increased with increasing age, and in all three conditions with a backrest the resonance frequency reduced with increasing body mass index. With the reclined rigid backrest, the resonance frequency was greater in the males (Table 8).

The regression coefficients for the association between age and resonance frequency were similar with all backrest conditions: over the 18 to 65 year age range of this study there was a 
mean increase of $1.1 \mathrm{~Hz}$ (reclined rigid backrest with $0.5 \mathrm{~ms}^{-2}$ r.m.s.; Table 6) to $1.7 \mathrm{~Hz}$ (reclined foam backrest with $1.0 \mathrm{~ms}^{-2}$ r.m.s.; Table 5). The addition of an $\mathrm{age}^{2}$ term to the regression analysis suggested the rate of 'stiffening' increased with increasing age, although this term did not significantly improve the overall fit of the model (in all cases, $p>0.2$ ).

In conditions with a backrest, increased body mass index (from 18 to $34 \mathrm{kgm}^{-2}$ ) was associated with a decrease in the resonance frequency of $0.56 \mathrm{~Hz}$ (reclined foam backrest at $1.0 \mathrm{~ms}^{-2}$ r.m.s.) to $1.7 \mathrm{~Hz}$ (reclined rigid backrest with $0.5 \mathrm{~ms}^{-2}$ r.m.s.). Since body mass index is associated with percentage body fat (e.g., [16]), the decreased resonance frequency may be caused by subjects with higher BMI having reduced coupling with the backrest, reducing the effective stiffness of the body measured at the seat surface, similar to the effects of increased thickness of foam with a reclined backrest [9].

When weight and height were added to the stepwise multiple regression models (in addition to $\mathrm{BMI}$ ) they were not found to be significant predictors of the resonance frequency. This suggests that body mass index was a better predictor of resonance frequency than either stature or body weight. When weight was entered into the multiple regression models in place of BMI, the resonance frequency obtained with $1.0 \mathrm{~ms}^{-2}$ r.m.s. decreased with increasing body weight when seated with the reclined rigid backrest $(p=0.01)$ and the reclined foam backrest $(p=0.019)$, but not with the other two backrest conditions (in both cases; $p>0.1$ ).

Females tended to have lower resonance frequencies than males after controlling for other factors, but the effect of gender on resonance frequency was only statistically significant with the reclined rigid backrest, where the mean difference was $0.57 \mathrm{~Hz}$ (Table 5). In contrast to this study, Lundström et al. [7] claimed a slightly lower absorbed power resonance frequency in females than in males when sitting upright with no backrest. The apparent difference may be due to the influence of confounding variables (e.g. age and BMI) whose effects have not been controlled in the statistical analysis of earlier studies.

\subsection{Other factors influencing apparent mass}

The $R^{2}$ values in the multiple regression analysis indicate the proportion of the variability in apparent mass accounted for by the predictors in the models. Between $19.5 \%$ and $38.9 \%$ of the 
variability in the apparent mass at resonance, and between $48.5 \%$ and $75.3 \%$ of the variability in resonance frequency was not explained by the models (Tables 5 and 6 ). This suggests other postural and anthropometric factors influenced the apparent masses of the subjects. They were asked to maintain a 'normal sitting posture' during the experiment but there will have been variations in posture between subjects. In addition, there will have been variations in subject build (e.g. distribution and proportion of muscle and fat) not fully reflected in their BMI, as well as changes in muscle tension.

\subsection{Inter-subject variability in the principal resonance}

The reduction in inter-subject variability in the apparent mass at resonance by normalising with respect to sitting weight is consistent with previous observations (e.g., [3]).

The reduction in the resonance frequency of the body as the magnitude of vibration increased was similar to previous findings (e.g. with subjects sitting with no backrest, [17]; with subjects supported by a reclined rigid backrest, [6]). The only subject characteristic affecting the nonlinearity was gender, where the reduction in resonance frequency with increased vibration magnitude was significantly less with females than males seated with the reclined rigid backrest. This difference in non-linearity between the genders may have been caused by effects of anatomical differences being more pronounced when supported by the reclined rigid backrest, consistent with the BMI affecting the resonance frequency in this posture (Table 5).

\subsection{Implications of the results}

The increase of $1.7 \mathrm{~Hz}$ in the resonance frequency with increasing age (from 18 to 65 years) was greater than the increase in the resonance frequency from no backrest to reclined rigid backrest $(0.9 \mathrm{~Hz})$ and greater than the maximum reduction in the resonance frequency associated with increasing the vibration magnitude from 0.5 to $1.5 \mathrm{~ms}^{-2}$ r.m.s. $(1.0 \mathrm{~Hz}$ ) (Table 2). The BMI and gender were also significant predictors of the resonance frequency, particularly with a reclined rigid backrest (Table 5). In some applications, such as when the apparent mass is being used to optimise a seat targeted at a specific population, the effects of age, BMI and gender might be sufficiently large for their effects to be taken into consideration. 
Reference values of apparent mass are defined in ISO 5982 [2] for the $50^{\text {th }}$ percentile seated human body, with no allowance for the effects of either the magnitude of vibration or contact with a backrest. Alternative reference values for apparent mass have been proposed taking into account: contact with a reclined rigid backrest, holding a steering wheel, input magnitude [4] and subject weight [5]. However, the small differences between the modulus and phase of the normalised apparent mass between subject groups in the present study, and the absence of any association between subject weight and normalised apparent mass at resonance (Table 7), suggests that reference values for apparent mass might be sufficiently defined by using the normalised apparent mass multiplied by the sitting weight of the target population.

The effects of subject characteristics on seat transmissibility are not yet well understood and so characteristics in addition to those affecting the apparent mass of the body may influence seat transmissibility, and some factors that influence the apparent mass may have little effect on seat transmissibility. Further investigation is required to understand the influence of subject characteristics on the vibration transmitted through seats.

\section{Conclusions}

Of the physical characteristics of subjects investigated in this study, subject mass had the greatest effect on the apparent mass at $0.6 \mathrm{~Hz}$, at resonance, and at $12 \mathrm{~Hz}$. Subject age, body mass index, and gender were associated with the principal resonance frequency in the apparent mass. There was a mean increase of $1.7 \mathrm{~Hz}$ in the resonance frequency as age increased from 18 to 65 years. As body mass index increased from 18 to $34 \mathrm{kgm}^{-2}$, the resonance frequency decreased by $1.7 \mathrm{~Hz}$. These changes were greater than the increase in resonance frequency between no backrest and a reclined rigid backrest $(0.9 \mathrm{~Hz})$, and also greater than the reduction in resonance frequency when increasing the magnitude of vibration from 0.5 to $1.5 \mathrm{~ms}^{-2}$ r.m.s. $(1.0 \mathrm{~Hz})$. It seems appropriate to consider the effects of age, BMI, and weight when defining reference values for the vertical apparent mass of the human body.

The variability in apparent mass between subjects at resonance was reduced when the effect of static weight was removed by normalisation (i.e. dividing the modulus of the apparent mass by the subject sitting weight), suggesting the required apparent mass may be obtained by 
multiplying the appropriate normalised apparent mass by the sitting weight of the target population.

\section{Acknowledgements}

The authors would like to acknowledge the helpful advice of Prof. Clive Osmond of the MRC epidemiology research centre on statistical methods and in particular the use of multiple regression models.

\section{References}

[1] L. Wei, M.J. Griffin, The prediction of seat transmissibility from measures of seat impedance. Journal of Sound and Vibration 214 (1998) 121-137.

[2] International Organization for Standardisation ISO 5982, Mechanical vibration and shockRange of idealized values to characterize seated-body biodynamic response under vertical vibration, International Standard, 2001.

[3] T.E. Fairley, M.J. Griffin, The apparent mass of the seated human body: vertical vibration. Journal of Biomechanics 22 (1989) 81-94.

[4] S. Rakheja, I. Stiharu, P.É. Boileau, Seated occupant apparent mass characteristics under automotive posture and vertical vibration. Journal of Sound and Vibration 253 (1) (2002) 57-75. [5] S.K. Patra, S. Rakheja, H. Nelisse, P.É. Boileau, J. Boutin, Seated occupant interactions with seat backrest and pan, and biodynamic responses under vertical vibration. Journal of Sound and Vibration 298 (3) (2006) 651-667.

[6] W. Wang, S. Rakheja, P.É. Boileau, Effects of sitting postures on biodynamic response of seated occupant under vertical vibration. International Journal of Industrial Ergonomics 34 (2004) 289-306.

[7] R. Lundstrom, P. Holmlund, L. Lindberg, Absorption of energy during vertical whole-body vibration exposure. Journal of Biomechanics 31 (4) (1998) 317-326.

[8] P. Holmlund, R. Lundström, L. Lindberg, Mechanical impedance of the human body in vertical direction. Applied Ergonomics 31 (2000) 415-422. 
[9] M.G.R. Toward, M.J. Griffin, Apparent mass of the human body in the vertical direction:

Effect of seat backrest. Journal of Sound and Vibration 327 (3-5) (2009) 657-669.

[10] Y. Matsumoto and M.J. Griffin, Dynamic response of the standing human body exposed to vertical vibration: influence of posture and vibration magnitude, Journal of Sound and Vibration 212 (1998) 85-107.

[11] Y. Huang, M.J. Griffin, Nonlinear dual-axis biodynamic response of the semi-supine human body during vertical whole-body vibration. Journal of Sound and Vibration 312 (1-2) (2008) 296315.

[12] S.K. Patra, S. Rakheja, H. Nelisse, P.É. Boileau, J. Boutin, Determination of reference values of apparent mass responses of seated occupants of different body masses under vertical vibration with and without a back support. International Journal of Industrial Ergonomics 38 (5-6) (2008) 483-498.

[13] N.J. Mansfield, M.J. Griffin, Effects of posture and vibration magnitude on apparent mass and pelvis rotation during exposure to whole-body vertical vibration. Journal of Sound and Vibration 253 (1) (2002) 93-107.

[14] S. Pheasant 1994 Bodyspace: Anthropometry, Ergonomics and the Design of work. Taylor \& Francis, USA. ISBN 0-85066-352-0.

[15] Department of Health. Health Survey for England 2007: Adult trend tables (2008). The NHS Information Centre for health and social care.

[16] D. Gallagher, M. Visser, D. Sepulveda, R.N. Pierson, T. Harris, S.B. Heymsfield, How useful is body mass index for comparison of body fatness across age, sex, and ethnic groups? American Journal of Epidemiology 143(3) (1996):228-239.

[17] Y. Matsumoto, M.J. Griffin, Effect of muscle tension on non-linearities in the apparent masses of seated subjects exposed to vertical whole-body vibration. Journal of Sound and Vibration 253 (2002) 77-92. 
Published as: Apparent mass of the human body in the vertical direction: Inter-subject variability Toward, M. G. R. \& Griffin, M. J. 14 Feb 2011 In : Journal of Sound and Vibration. 330, 4, p. 827-841.

Table 1 Mean and standard deviations of subject characteristics (UK population in brackets).

\begin{tabular}{|c|c|c|c|c|c|c|c|c|c|}
\hline & \multicolumn{3}{|c|}{ All subjects } & \multicolumn{3}{|c|}{ Women (39 subjects) } & \multicolumn{3}{|c|}{ Men (41 subjects) } \\
\hline & Mean & s.d. & Range & Mean & s.d. & Range & Mean & s.d. & Range \\
\hline Age, years & 33.7 & 13.1 & $18-65$ & 33.1 & 11.2 & $19-56$ & 33.8 & 14.8 & $18-65$ \\
\hline Weight, kg & 70.5 & 13.4 & $46-103$ & $62.8\left(69.7^{a}\right)$ & 11.5 & $46-98$ & $77.1\left(83.5^{a}\right)$ & 11.3 & $58-103$ \\
\hline Stature, cm & 171.0 & 11.3 & $149-192$ & $162.6\left(161.0^{b}\right)$ & 8.9 & $149-185$ & $178.5\left(174.0^{b}\right)$ & 7.1 & $164-192$ \\
\hline Body mass index, $\mathrm{kgm}^{-2}$ & 24.1 & 3.8 & $18-34$ & $23.8\left(26.8^{a}\right)$ & 4.2 & $18-34$ & $24.2\left(27.1^{a}\right)$ & 3.4 & $18-31$ \\
\hline Knee height, cm & 52.7 & 4.2 & $45-61$ & $50.1\left(50.0^{b}\right)$ & 3.4 & $45-61$ & $55.2\left(54.5^{b}\right.$ & 3.1 & $50-61$ \\
\hline Buttock knee length, cm & 59.6 & 4.2 & $48-69$ & $57.9\left(57.0^{b}\right)$ & 3.8 & $48-66$ & $61.0\left(59.5^{b}\right)$ & 4.0 & $56-69$ \\
\hline Sitting height, $\mathrm{cm}$ & 85.8 & 5.1 & $76-101$ & $82.7\left(85.0^{b}\right)$ & 3.4 & $76-92$ & $88.7\left(91.0^{b}\right)$ & 4.7 & $80-101$ \\
\hline
\end{tabular}

${ }^{a}$ Adults aged $16+[15]$

${ }^{b}$ Anthropometric estimates for British adults aged 19-65 [14] 
Published as: Apparent mass of the human body in the vertical direction: Inter-subject variability Toward, M. G. R. \& Griffin, M. J. 14 Feb 2011 In : Journal of Sound and Vibration. 330, 4, p. 827-841.

Table 2 Effect of backrest contact and vibration magnitude on the primary resonance frequency and the apparent mass at resonance, at $0.6 \mathrm{~Hz}$, and at $12.0 \mathrm{~Hz}$. Means (and standard deviations) of 80 subjects.

\begin{tabular}{lllll}
\hline & $\begin{array}{l}\text { Resonance } \\
\text { frequency, } \\
\mathrm{Hz}\end{array}$ & $\begin{array}{l}\text { Apparent mass at } \\
\text { resonance, } \\
\mathrm{kg}\end{array}$ & $\begin{array}{l}\text { Apparent mass at } \\
0.6 \mathrm{~Hz}, \\
\mathrm{~kg}\end{array}$ & $\begin{array}{l}\text { Apparent mass } \\
\text { at } 12.0 \mathrm{~Hz}, \\
\mathrm{~kg}\end{array}$ \\
\hline $\begin{array}{llll}\text { Backrest contact }\left(1.0 \mathrm{~ms}^{-2} \text { r.m.s.) }\right. \\
\quad \text { No backrest }\end{array}$ & $4.9(0.6)$ & $98.7(24.9)$ & $62.0(12.6)$ & $27.8(6.6)$ \\
$\quad$ Upright rigid backrest & $5.2(0.7)$ & $89.2(24.8)$ & $58.0(12.2)$ & $32.6(6.3)$ \\
$\quad$ Reclined rigid backrest & $5.9(0.8)$ & $83.1(22.6)$ & $55.0(12.3)$ & $34.7(6.9)$ \\
$\quad$ Reclined foam backrest & $5.0(0.7)$ & $93.8(23.1)$ & $57.6(12.1)$ & $27.5(6.2)$ \\
Input magnitude (no backrest) & & & & \\
$0.5 \mathrm{~ms}^{-2}$ r.m.s. & $5.2(0.7)$ & $94.9(25.7)$ & $59.8(14.5)$ & $29.7(7.1)$ \\
$1.0 \mathrm{~ms}^{-2}$ r.m.s. & $4.9(0.6)$ & $98.7(24.9)$ & $62.0(12.6)$ & $27.8(6.6)$ \\
$1.5 \mathrm{~ms}^{-2}$ r.m.s. & $4.7(0.6)$ & $99.8(24.9)$ & $62.1(12.5)$ & $26.2(6.1)$ \\
Input magnitude (reclined rigid backrest) & & & & \\
$0.5 \mathrm{~ms}^{-2}$ r.m.s. & $6.4(1.0)$ & $81.2(22.9)$ & $53.2(13.6)$ & $35.9(7.4)$ \\
$1.0 \mathrm{~ms}^{-2}$ r.m.s. & $5.9(0.8)$ & $83.1(22.6)$ & $55.0(12.3)$ & $34.7(6.9)$ \\
$1.5 \mathrm{~ms}^{-2}$ r.m.s. & $5.4(0.8)$ & $84.0(22.1)$ & $56.0(11.9)$ & $33.0(6.4)$ \\
\hline
\end{tabular}


Table 3 Effect of subject physical characteristics on their primary resonance frequency and their apparent mass at resonance, at $0.6 \mathrm{~Hz}$ and at $12.0 \mathrm{~Hz}$ with no backrest and with an excitation magnitude of $1.0 \mathrm{~ms}^{-2}$ r.m.s. Means (and standard deviations) of 20 subjects, except for gender (41 males, 39 females).

\begin{tabular}{|c|c|c|c|c|}
\hline & $\begin{array}{l}\text { Resonance } \\
\text { frequency, } \\
\mathrm{Hz}\end{array}$ & $\begin{array}{l}\text { Apparent mass at } \\
\text { resonance, } \\
\mathrm{kg}\end{array}$ & $\begin{array}{l}\text { Apparent mass at } \\
0.6 \mathrm{~Hz} \text {, } \\
\mathrm{kg}\end{array}$ & $\begin{array}{l}\text { Apparent mass at } \\
12.0 \mathrm{~Hz}, \\
\mathrm{~kg}\end{array}$ \\
\hline \multicolumn{5}{|c|}{ Age, years: Median (min, max) } \\
\hline $21(18,23)$ & $4.6(0.5)$ & $96.8(21.6)$ & $61.5(11.1)$ & $26.2(5.7)$ \\
\hline $25(24,27)$ & $4.8(0.5)$ & $99.3(27.0)$ & 59.6 ( 12.5$)$ & $26.8(5.7)$ \\
\hline $35(28,45)$ & $4.9(0.4)$ & $93.6(28.3)$ & $59.7(14.9)$ & $25.4(5.4)$ \\
\hline $53(45,65)$ & $5.5(0.8)$ & $102.6(23.8)$ & $65.1(12.7)$ & $32.8(7.0)$ \\
\hline \multicolumn{5}{|l|}{ Gender: Median (min, max) } \\
\hline Female & $4.9(0.7)$ & $86.0(20.6)$ & $56.4(12.1)$ & $25.5(5.8)$ \\
\hline Male & $5.0(0.6)$ & $110.2(23.4)$ & $66.6(11.6)$ & $30.1(6.5)$ \\
\hline \multicolumn{5}{|c|}{ Weight, kg: Median (min, $\max$ ) } \\
\hline $54(46,60)$ & $5.1(0.8)$ & $71.2(10.1)$ & $47.7(6.1)$ & $22.9(3.9)$ \\
\hline $64(60,69)$ & $4.9(0.7)$ & 88.7 ( 9.5$)$ & $56.4(6.0)$ & $26.3(4.6)$ \\
\hline $74(69,80)$ & $4.7(0.6)$ & $106.0(14.8)$ & $67.3(4.4)$ & $27.9(4.9)$ \\
\hline $88(80,103)$ & $5.0(0.6)$ & $126.4(20.8)$ & $74.6(12.2)$ & $34.1(6.9)$ \\
\hline \multicolumn{5}{|c|}{ Stature, $\mathrm{cm}$ : Median (min, $\max$ ) } \\
\hline $156(149,163)$ & $4.9(0.8)$ & 79.5 ( 17.3$)$ & $52.3(10.5)$ & $24.7(5.0)$ \\
\hline $167(163,171)$ & $5.0(0.7)$ & 89.3 ( 18.4$)$ & 58.7 ( 10.9$)$ & $26.3(6.3)$ \\
\hline $176(171,181)$ & $5.0(0.6)$ & $104.6(24.1)$ & $64.0(10.7)$ & $30.8(7.7)$ \\
\hline $185(181,192)$ & $4.8(0.5)$ & $119.0(21.1)$ & $70.9(12.1)$ & $29.3(5.4)$ \\
\hline \multicolumn{5}{|c|}{ BMI, $\mathrm{kgm}^{-2}:$ Median (min, max) } \\
\hline $20(18,21)$ & $5.1(0.7)$ & $77.6(14.1)$ & $50.5(7.7)$ & $24.2(4.9)$ \\
\hline $22(21,23)$ & $4.7(0.6)$ & $92.3(18.0)$ & $59.2(8.6)$ & $25.4(4.8)$ \\
\hline $25(24,26)$ & $5.0(0.7)$ & $107.7(22.9)$ & $64.4(11.1)$ & $28.5(5.1)$ \\
\hline $31(26,34)$ & $4.9(0.6)$ & $114.8(26.3)$ & 71.7 ( 13.3 ) & $33.1(7.5)$ \\
\hline
\end{tabular}


Published as: Apparent mass of the human body in the vertical direction: Inter-subject variability Toward, M. G. R. \& Griffin, M. J. 14 Feb 2011 In : Journal of Sound and Vibration. 330, 4, p. 827-841.

Table 4 Bivariate regression coefficients showing the influence of subject physical characterises on features of their apparent mass $\left(1.0 \mathrm{~ms}^{-2}\right.$ r.m.s. with no backrest).

\begin{tabular}{|c|c|c|c|c|c|c|c|c|}
\hline \multirow[t]{2}{*}{ Variables } & \multicolumn{2}{|c|}{$\begin{array}{l}\text { Resonance } \\
\text { frequency, } \mathrm{Hz}\end{array}$} & \multicolumn{2}{|c|}{$\begin{array}{l}\text { Apparent mass at } \\
\text { resonance, } \mathrm{kg}\end{array}$} & \multicolumn{2}{|c|}{$\begin{array}{l}\text { Apparent mass } \\
\text { at } 0.6 \mathrm{~Hz}, \mathrm{~kg}\end{array}$} & \multicolumn{2}{|c|}{$\begin{array}{l}\text { Apparent mass } \\
\text { at } 12 \mathrm{~Hz}, \mathrm{~kg}\end{array}$} \\
\hline & $B \quad p$ & SEB & $B \quad p$ & SEB & $B \quad p$ & SEB & $B \quad p$ & SEB \\
\hline Age (years) & $0.027^{* * *}$ & 0.004 & 0.150 & 0.217 & 0.131 & 0.109 & 0.196 *** & 0.054 \\
\hline Gender $($ female $=0 ;$ male $=1$ ) & 0.219 & 0.134 & $25.465^{* * *}$ & 4.876 & $10.877^{* * *}$ & 2.583 & $4.985^{* * *}$ & 1.401 \\
\hline Weight, kg & 0.000 & 0.005 & $1.640^{* * *}$ & 0.107 & $0.848^{* * *}$ & 0.049 & $0.341^{* * *}$ & 0.042 \\
\hline Stature, $\mathrm{cm}$ & 0.001 & 0.006 & $1.280^{* * *}$ & 0.206 & $0.627^{* * *}$ & 0.105 & $0.171^{* *}$ & 0.064 \\
\hline $\mathrm{BMI}, \mathrm{kgm}^{-2}$ & -0.004 & 0.018 & $3.700 * * *$ & 0.635 & $2.013^{* * *}$ & 0.308 & $1.012^{* * *}$ & 0.167 \\
\hline Knee height, cm & 0.000 & 0.017 & $3.692^{* * *}$ & 0.540 & $2.001^{* * *}$ & 0.272 & $0.543^{*}$ & 0.177 \\
\hline Buttock-knee length, cm & -0.009 & 0.016 & 2.686 *** & 0.614 & $1.360^{* * *}$ & 0.310 & 0.434 * & 0.176 \\
\hline Sitting height, $\mathrm{cm}$ & -0.009 & 0.013 & $2.401^{* * *}$ & 0.487 & $1.241^{* \star *}$ & 0.244 & 0.289 * & 0.145 \\
\hline
\end{tabular}

$B$ : regression coefficient; SEB: standard error of the regression coefficient. ${ }^{*} p<0.05,{ }^{* *} p<0.01,{ }^{* * *} p<0.001$. 
Table 5 Multiple regression analysis showing the influence of significant subject physical characteristics (as well as age and gender) on features of their apparent mass with each backrest condition (1.0 ms $\mathrm{ms}^{-2}$ r.m.s. excitation).

\begin{tabular}{|c|c|c|c|c|c|c|c|c|}
\hline & \multicolumn{2}{|c|}{ No backrest } & \multicolumn{2}{|c|}{ Upright rigid } & \multicolumn{2}{|c|}{ Reclined rigid } & \multicolumn{2}{|c|}{ Reclined foam } \\
\hline & $B \quad p$ & SEB & $B \quad p$ & SEB & $B \quad p$ & SEB & $B \quad p$ & SEB \\
\hline \multicolumn{9}{|l|}{ Resonance frequency, $\mathrm{Hz}$} \\
\hline Age (years) & $0.028 * * *$ & 0.004 & $0.025^{* * *}$ & 0.006 & $0.027 * * *$ & 0.006 & $0.036 * * *$ & 0.004 \\
\hline Gender (female $=0 ;$ male $=1$ ) & 0.190 & 0.108 & 0.222 & 0.144 & $0.567^{* * *}$ & 0.154 & 0.169 & 0.106 \\
\hline $\mathrm{BMI}, \mathrm{kgm}^{-2}$ & -0.026 & 0.015 & $-0.055^{* *}$ & 0.020 & $-0.088^{* * *}$ & 0.021 & $-0.035^{* *}$ & 0.014 \\
\hline Constant & 4.496 & & 5.618 & & 6.781 & & 4.488 & \\
\hline $\mathrm{R}^{2}, \%$ & 39.4 & & 27.5 & & 37.3 & & 51.5 & \\
\hline \multicolumn{9}{|l|}{ Apparent mass at resonance, $\mathrm{kg}$} \\
\hline Age (years) & -0.131 & 0.108 & 0.045 & 0.134 & 0.066 & 0.097 & 0.178 & 0.091 \\
\hline Gender (female $=0 ;$ male $=1$ ) & 3.937 & 3.262 & 3.288 & 4.178 & 3.778 & 2.933 & 0.495 & 2.763 \\
\hline Weight, kg & $1.584^{* * *}$ & 0.126 & $1.399 * * *$ & 0.156 & $1.384^{* * *}$ & 0.111 & $1.500^{* * *}$ & 0.105 \\
\hline Constant & -10.230 & & -11.350 & & -17.810 & & -17.346 & \\
\hline $\mathrm{R}^{2}, \%$ & 76.7 & & 64.9 & & 77.0 & & 80.5 & \\
\hline \multicolumn{9}{|l|}{ Apparent mass at $0.6 \mathrm{~Hz}, \mathrm{~kg}$} \\
\hline Age (years) & -0.017 & 0.051 & 0.032 & 0.062 & 0.044 & 0.049 & 0.019 & 0.045 \\
\hline Gender (female $=0 ;$ male $=1$ ) & -1.030 & 1.540 & 0.311 & 1.931 & $-2.998 *$ & 1.483 & -0.074 & 1.357 \\
\hline Weight, kg & $0.871^{* * *}$ & 0.059 & $0.737^{* * *}$ & 0.072 & $0.867^{* * *}$ & 0.056 & $0.816^{* * *}$ & 0.051 \\
\hline Constant & 1.876 & & 5.499 & & -5.579 & & -0.065 & \\
\hline $\mathrm{R}^{2}, \%$ & 79.6 & & 69.0 & & 80.2 & & 82.7 & \\
\hline \multicolumn{9}{|l|}{ Apparent mass at $12 \mathrm{~Hz}, \mathrm{~kg}$} \\
\hline Age (years) & $0.143^{* * *}$ & 0.041 & $0.115^{* *}$ & 0.042 & 0.065 & 0.037 & $0.132^{* * *}$ & 0.033 \\
\hline Gender (female $=0 ;$ male $=1$ ) & 0.635 & 1.220 & 0.090 & 1.319 & $2.320^{*}$ & 1.123 & -1.748 & 1.002 \\
\hline Weight, kg & $0.304^{* * *}$ & 0.047 & $0.276^{* * *}$ & 0.049 & $0.347^{* * *}$ & 0.043 & $0.354^{* * *}$ & 0.038 \\
\hline Constant & 1.356 & & 9.557 & & $7.067^{* *}$ & & -0.854 & \\
\hline $\mathrm{R}^{2}, \%$ & 54.0 & & 45.2 & & 64.2 & & 63.9 & \\
\hline
\end{tabular}

$B$ : regression coefficient; SEB: standard error of the regression coefficient. $R^{2}$ : percentage of experimental variation accounted for by the model. ${ }^{*} p<0.05,{ }^{* *} p<0.01,{ }^{* \star *} p<0.001$. 
Table 6 Multiple regression analysis showing the effect of excitation magnitude on the influence of significant subject physical characteristics (as well as age and gender) on features of their apparent mass. See Table 5 for excitation at $1.0 \mathrm{~ms}^{-2}$ r.m.s.

\begin{tabular}{|c|c|c|c|c|c|c|c|c|}
\hline & \multicolumn{4}{|c|}{ No backrest } & \multicolumn{4}{|c|}{ Reclined rigid backrest } \\
\hline & \multicolumn{2}{|c|}{$0.5 \mathrm{~ms}^{-2}$ r.m.s. } & \multicolumn{2}{|c|}{$1.5 \mathrm{~ms}^{-2}$ r.m.s. } & \multicolumn{2}{|c|}{$0.5 \mathrm{~ms}^{-2}$ r.m.s. } & \multicolumn{2}{|c|}{$1.5 \mathrm{~ms}^{-2}$ r.m.s. } \\
\hline & $B \quad p$ & SEB & $B \quad p$ & SEB & $B \quad p$ & SEB & $B \quad p$ & SEB \\
\hline \multicolumn{9}{|l|}{ Resonance frequency } \\
\hline Age (years) & $0.024^{* * *}$ & 0.005 & $0.029 * * *$ & 0.004 & 0.024 ** & 0.008 & 0.026 *** & 0.006 \\
\hline Gender (female $=0 ;$ male $=1$ ) & 0.320 & 0.131 & 0.154 & 0.110 & 0.366 & 0.196 & 0.376 * & 0.150 \\
\hline $\mathrm{BMI}, \mathrm{kgm}^{-2}$ & -0.024 & 0.018 & -0.026 & 0.015 & $-0.107^{* * *}$ & 0.027 & $-0.094 * * *$ & 0.020 \\
\hline Constant & 4.799 & & 4.309 & & 7.962 & & 6.626 & \\
\hline $\mathrm{R}^{2}, \%$ & 31.5 & & 39.0 & & 24.7 & & 34.1 & \\
\hline \multicolumn{9}{|l|}{ Apparent mass at resonance } \\
\hline Age (years) & -0.018 & 0.144 & -0.068 & 0.110 & 0.058 & 0.109 & 0.098 & 0.095 \\
\hline Gender (female $=0$; male $=1$ ) & 4.418 & 4.418 & 2.024 & 3.355 & 4.258 & 3.307 & 0.350 & 2.905 \\
\hline Weight, kg & $1.420 * * *$ & 0.170 & $1.573^{* * *}$ & 0.127 & $1.348^{* * *}$ & 0.125 & $1.417^{* * *}$ & 0.110 \\
\hline Constant & -6.998 & 11.330 & -9.330 & & -17.213 & & -18.885 & \\
\hline $\mathrm{R}^{2}, \%$ & 61.1 & & 75.2 & & 71.7 & & 76.5 & \\
\hline \multicolumn{9}{|l|}{ Apparent mass at $0.6 \mathrm{~Hz}$} \\
\hline Age (years) & 0.019 & 0.096 & 0.029 & 0.051 & -0.002 & 0.076 & 0.079 & 0.045 \\
\hline Gender (female $=0 ;$ male $=1$ ) & -0.946 & 2.937 & -1.104 & 1.550 & -2.893 & 2.292 & -2.069 & 1.374 \\
\hline Weight, kg & $0.763^{* \star *}$ & 0.113 & $0.841^{* \star *}$ & 0.059 & $0.841^{* \star *}$ & 0.087 & $0.822^{* * *}$ & 0.052 \\
\hline Constant & 5.807 & & 2.687 & & -4.149 & & -3.196 & \\
\hline $\mathrm{R}^{2}, \%$ & 46.4 & & 78.9 & & 61.0 & & 81.6 & \\
\hline \multicolumn{9}{|l|}{ Apparent mass at $12 \mathrm{~Hz}$} \\
\hline Age (years) & $0.124^{* \star}$ & 0.046 & $0.151^{* * *}$ & 0.036 & 0.092 & 0.046 & $0.085^{* *}$ & 0.031 \\
\hline Gender (female $=0 ;$ male $=1$ ) & 1.556 & 1.416 & 0.925 & 1.083 & 3.108 * & 1.410 & 1.658 & 0.949 \\
\hline Weight, kg & $0.295^{* * *}$ & 0.054 & $0.267^{* * *}$ & 0.041 & $0.293^{* * *}$ & 0.053 & $0.340^{* * *}$ & 0.036 \\
\hline Constant & 3.931 & & 1.946 & & 10.735 & & 5.496 & \\
\hline $\mathrm{R}^{2}, \%$ & 47.6 & & 56.3 & & 50.3 & & 69.6 & \\
\hline
\end{tabular}

$B$ : regression coefficient; SEB: standard error of the regression coefficient.

$R^{2}$ : percentage of experimental variation accounted for by the model.

${ }^{*} p<0.05,{ }^{* *} p<0.01,{ }^{* * *} p<0.001$. 
Table 7 Multiple regression analysis showing the influence of significant subject physical characteristics (as well as age and gender) on features of their normalized apparent mass with each backrest condition (1.0 ms m.m.s. $^{-2}$. excitation).

\begin{tabular}{|c|c|c|c|c|c|c|c|c|}
\hline & \multicolumn{2}{|c|}{ No backrest } & \multicolumn{2}{|c|}{ Upright rigid } & \multicolumn{2}{|c|}{ Reclined rigid } & \multicolumn{2}{|c|}{ Reclined foam } \\
\hline & $B \quad p$ & SEB & $B$ & $p \quad S E B$ & $B \quad p$ & SEB & $B \quad p$ & SEB \\
\hline \multicolumn{9}{|l|}{$\begin{array}{l}\text { Normalised apparent mass at } \\
\text { resonance }\end{array}$} \\
\hline Age (years) & -0.001 & 0.001 & 0.000 & 0.001 & 0.000 & 0.001 & 0.002 & 0.001 \\
\hline Gender (female $=0 ;$ male $=1$ ) & 0.085 & 0.043 & 0.019 & 0.047 & $0.102^{* *}$ & 0.035 & -0.002 & 0.047 \\
\hline Weight, kg & 0.003 & 0.002 & 0.002 & 0.002 & -0.001 & 0.001 & 0.002 & 0.002 \\
\hline Knee height, $\mathrm{cm}$ & 0.000 & 0.006 & 0.012 & 0.007 & $0.013^{* *}$ & 0.005 & 0.007 & 0.007 \\
\hline Constant & 1.368 & & 0.735 & & 0.780 & & 1.068 & \\
\hline $\mathrm{R}^{2}, \%$ & 20.3 & & 21.8 & & 38.1 & & 12.2 & \\
\hline \multicolumn{9}{|l|}{ Normalised apparent mass at $12 \mathrm{~Hz}$} \\
\hline Age (years) & $0.002^{*}$ & 0.001 & 0.002 & 0.001 & 0.000 & 0.001 & $0.002^{* *}$ & 0.001 \\
\hline Gender $($ female $=0 ;$ male $=1$ ) & $0.059 *$ & 0.029 & 0.011 & 0.030 & $0.098^{* *}$ & 0.029 & -0.009 & 0.023 \\
\hline Weight, kg & 0.008 & 0.008 & 0.009 & 0.008 & $0.016^{*}$ & 0.008 & 0.006 & 0.006 \\
\hline Stature, $\mathrm{cm}$ & -0.010 & 0.007 & -0.011 & 0.007 & $-0.018 * *$ & 0.007 & -0.007 & 0.005 \\
\hline $\mathrm{BMI}, \mathrm{kgm}^{-2}$ & -0.024 & 0.023 & -0.033 & 0.023 & $-0.056^{*}$ & 0.023 & -0.019 & 0.018 \\
\hline Constant & 2.145 & & 2.475 & & 3.910 & & 1.593 & \\
\hline $\mathrm{R}^{2}, \%$ & 18.4 & & 20.2 & & 33.0 & & 21.0 & \\
\hline
\end{tabular}

$B$ : regression coefficient; $S E B$ : standard error of the regression coefficient. $R^{2}$ : percentage of experimental variation accounted for by the model. ${ }^{*} p<0.05,{ }^{* *} p<0.01,{ }^{* \star *} p<0.001$. 
Published as: Apparent mass of the human body in the vertical direction: Inter-subject variability Toward, M. G. R. \& Griffin, M. J. 14 Feb 2011 In : Journal of Sound and Vibration. 330, 4, p. 827-841.

Table 8 Dimensionless beta coefficients, $\beta$, showing the relative strength of significant subject physical characteristics (as well as age and gender) in the multiple regression models for each backrest condition (1.0 $\mathrm{ms}^{-2}$ r.m.s. excitation).

\begin{tabular}{|c|c|c|c|c|}
\hline & No backrest & Upright rigid & Reclined rigid & Reclined foam \\
\hline & $\beta$ & $\beta$ & $\beta$ & $\beta$ \\
\hline \multicolumn{5}{|l|}{ Resonance frequency } \\
\hline Gender $($ female $=0 ;$ male $=1)$ & 0.16 & 0.16 & 0.34 *** & 0.13 \\
\hline $\mathrm{BMI}, \mathrm{kgm}^{-2}$ & -0.16 & $-0.29 * *$ & $-0.39 * * *$ & $-0.20 * *$ \\
\hline Gender $($ female $=0 ;$ male $=1)$ & 0.08 & 0.07 & 0.08 & 0.01 \\
\hline Weight, kg & $0.84^{* * *}$ & $0.76 * * *$ & $0.82 * * *$ & $0.87^{* * *}$ \\
\hline \multicolumn{5}{|l|}{ Apparent mass at $0.6 \mathrm{~Hz}$} \\
\hline Age (years) & -0.02 & 0.03 & 0.05 & 0.02 \\
\hline Gender $($ female $=0 ;$ male $=1)$ & -0.04 & 0.01 & $-0.12 *$ & 0.00 \\
\hline Gender (female $=0 ;$ male $=1$ ) & 0.05 & 0.01 & $0.17^{*}$ & -0.14 \\
\hline Weight, kg & $0.61 * * *$ & $0.60 * * *$ & $0.67^{* * *}$ & $0.77 * * *$ \\
\hline
\end{tabular}

$\beta$ : standardized regression coefficient.

$R^{2}$ : percentage of experimental variation accounted for by the model.

${ }^{*} p<0.05,{ }^{*} p<0.01,{ }^{* * *} p<0.001$. 


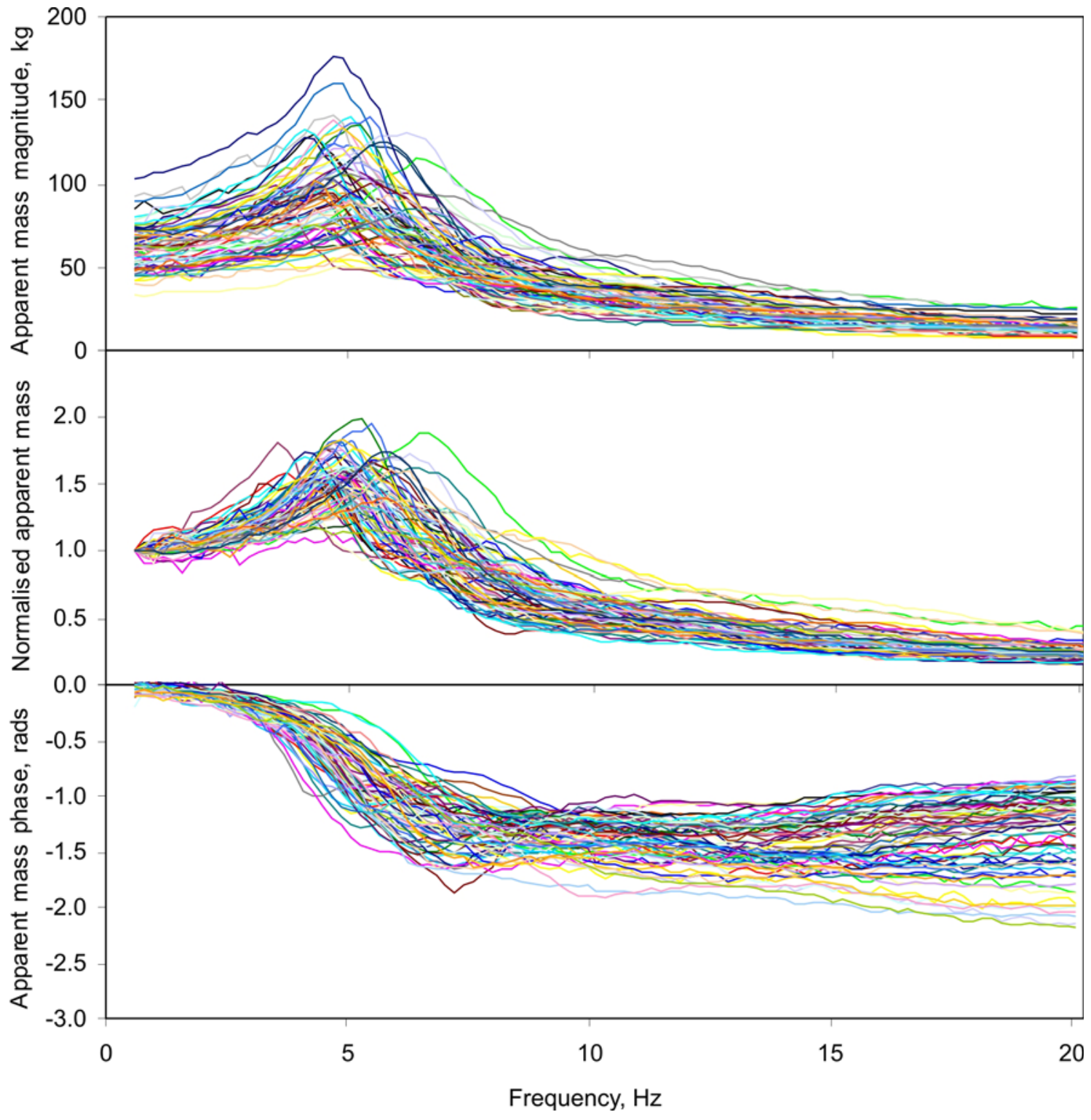

Figure 1 Apparent masses of 80 adults (no backrest, excitation magnitude $1.0 \mathrm{~ms}^{-2}$ r.m.s.). 
Published as: Apparent mass of the human body in the vertical direction: Inter-subject variability Toward, M. G. R. \& Griffin, M. J. 14 Feb 2011 In : Journal of Sound and Vibration. 330, 4, p. 827-841.

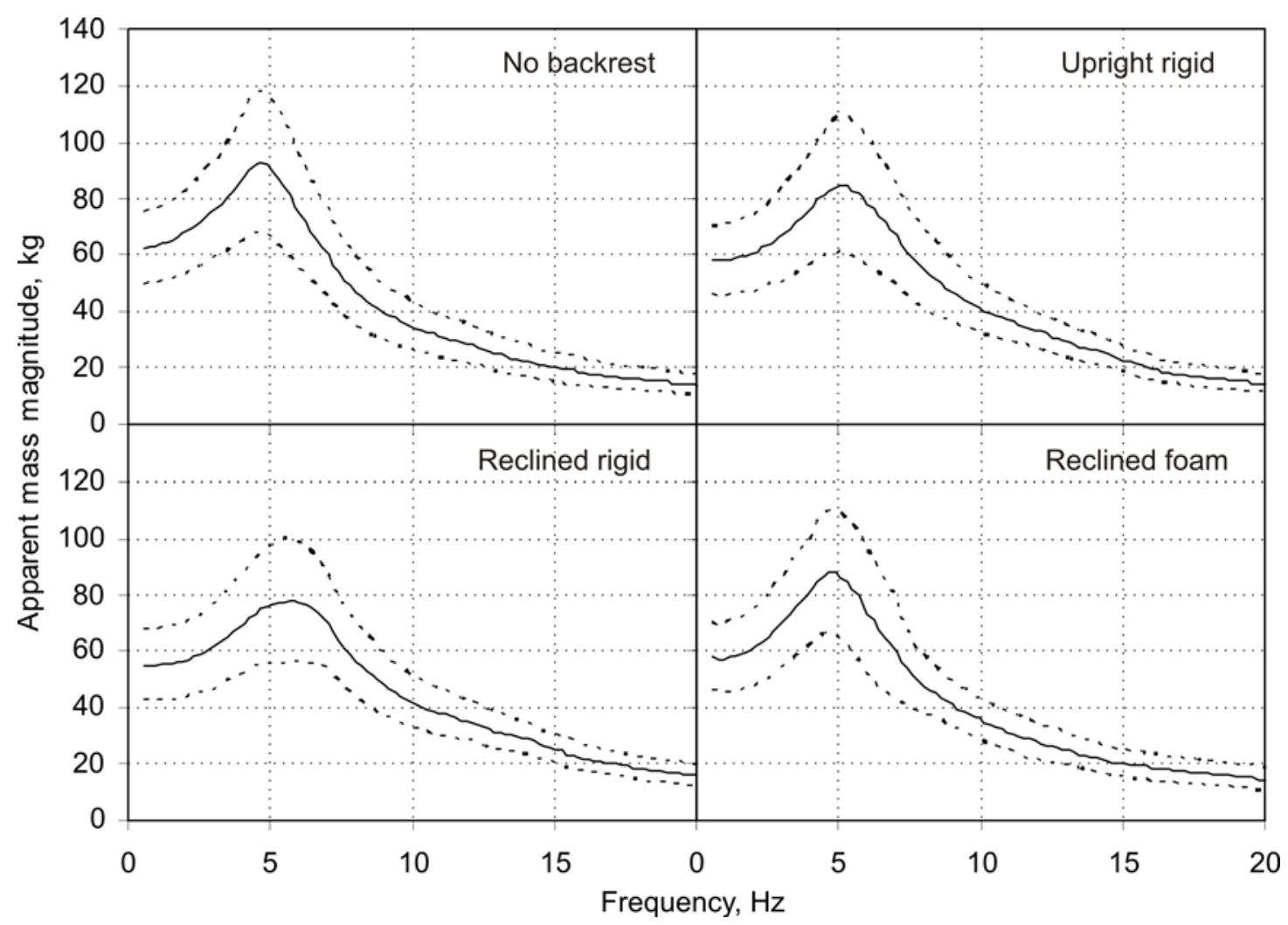

Figure 2 Effect of the seat backrest on mean apparent mass and inter-subject variability; $1.0 \mathrm{~ms}^{-2}$ r.m.s excitation: mean $(\longrightarrow)$ and \pm 1 s.d. $(\cdots \cdots)$. 


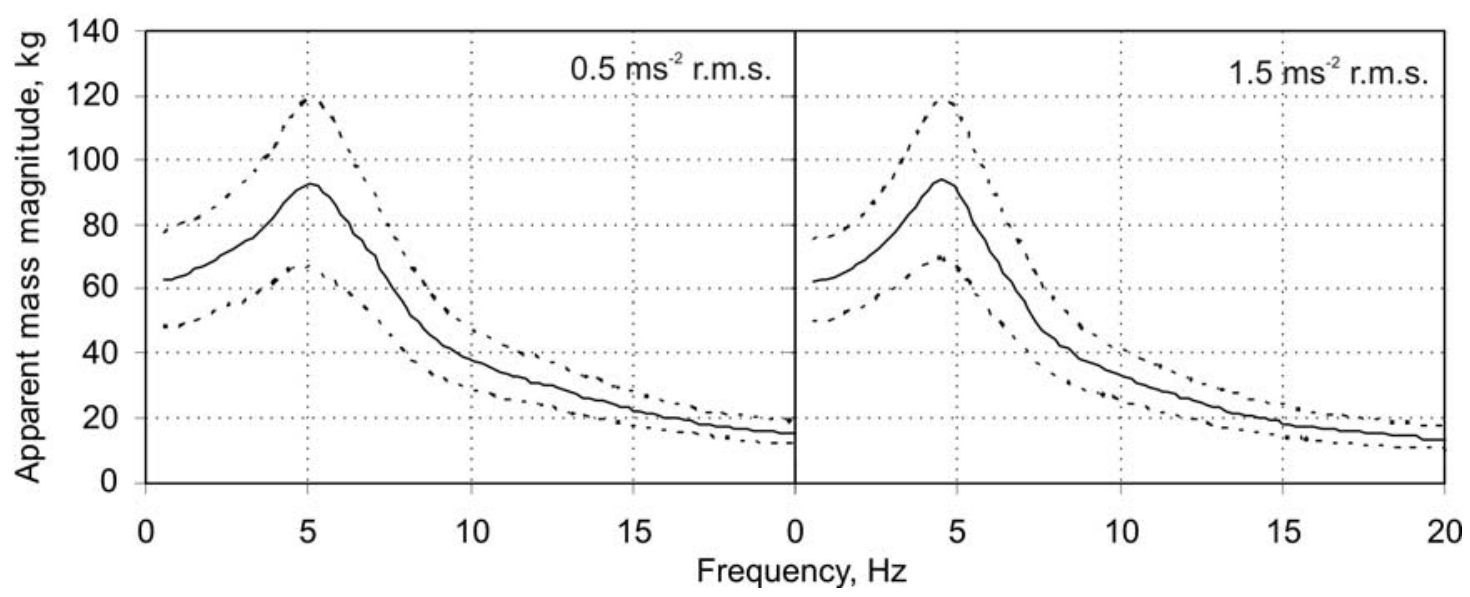

Figure 3 Effect of input magnitude on apparent mass and inter-subject variability; no backrest contact: mean $(\longrightarrow)$ and mean \pm 1 s.d. $(\cdots)$ ). For excitation at $1.0 \mathrm{~ms}^{-2}$ r.m.s., see Figure 2 (no backrest). 


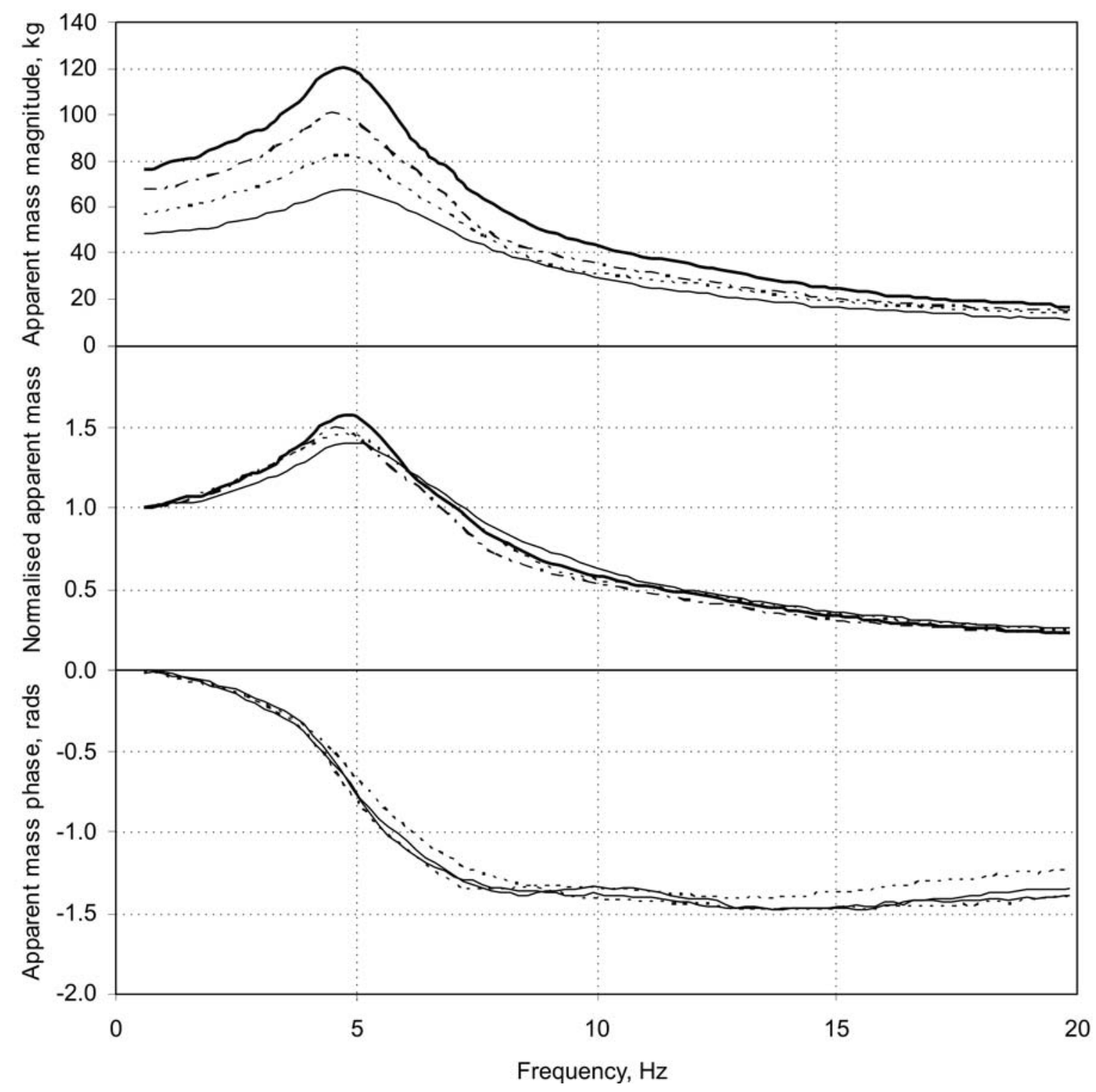

Figure 4 Effect of subject weight on measured and normalised apparent mass (no backrest and $1.0 \mathrm{~ms}^{-2}$ r.m.s excitation); subjects grouped by weight (20 per group) with mean weights: $54 \mathrm{~kg}$ $(-), 64 \mathrm{~kg}(\cdots \cdots), 74 \mathrm{~kg}(\cdot-\cdot-)$, and $88 \mathrm{~kg}(-)$. 
Published as: Apparent mass of the human body in the vertical direction: Inter-subject variability Toward, M. G. R. \& Griffin, M. J. 14 Feb 2011 In : Journal of Sound and Vibration. 330, 4, p. 827-841.

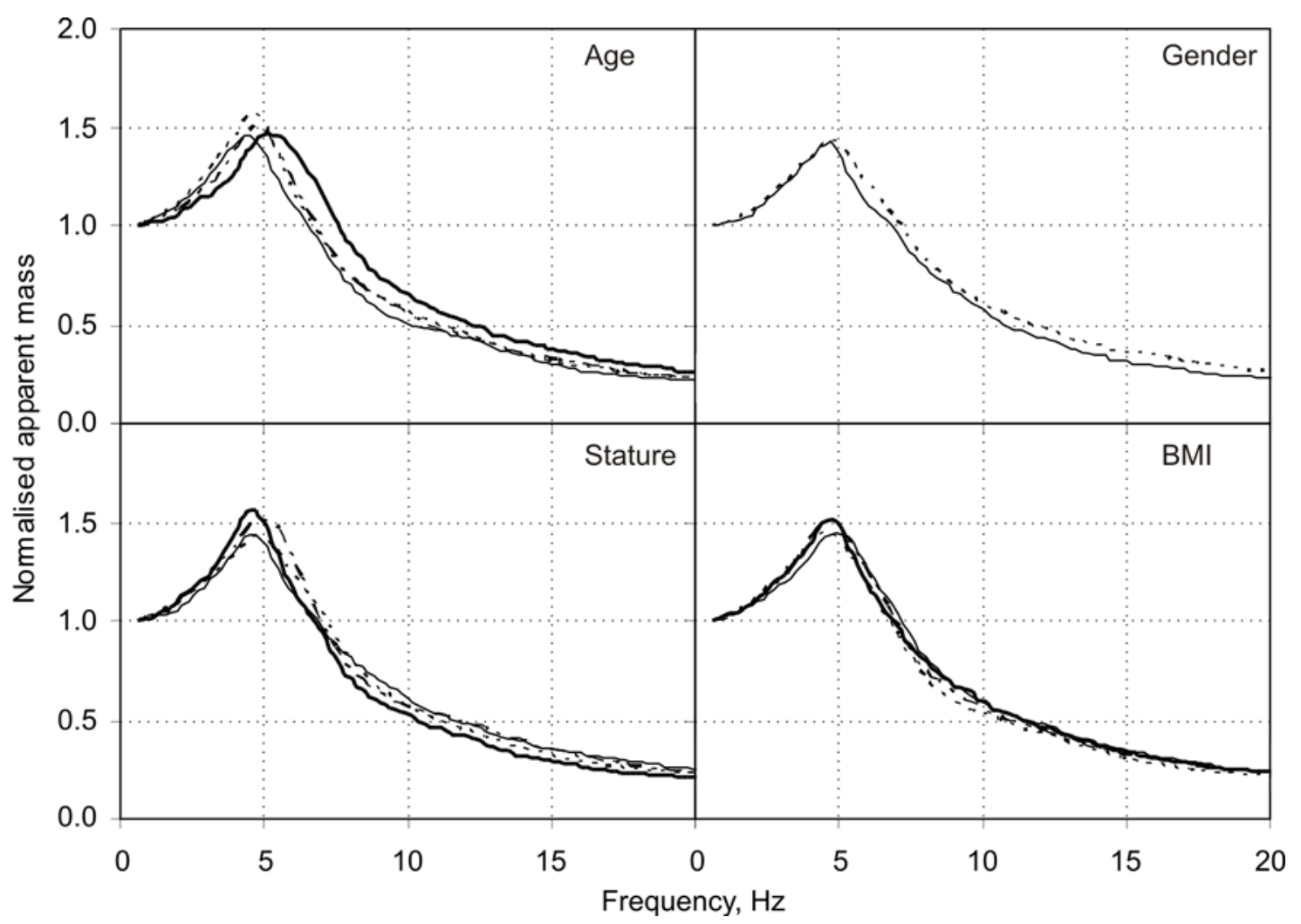

Figure 5 Effect of physical characteristics on normalised apparent mass (no backrest, $1.0 \mathrm{~ms}^{-2}$ r.m.s excitation); subjects grouped (see Table 3 for details) by physical characteristic: Group 1 $(-)$, Group $2(\cdots \cdot)$, Group $3(\cdot-\cdot-)$ and Group $4(-)$. 

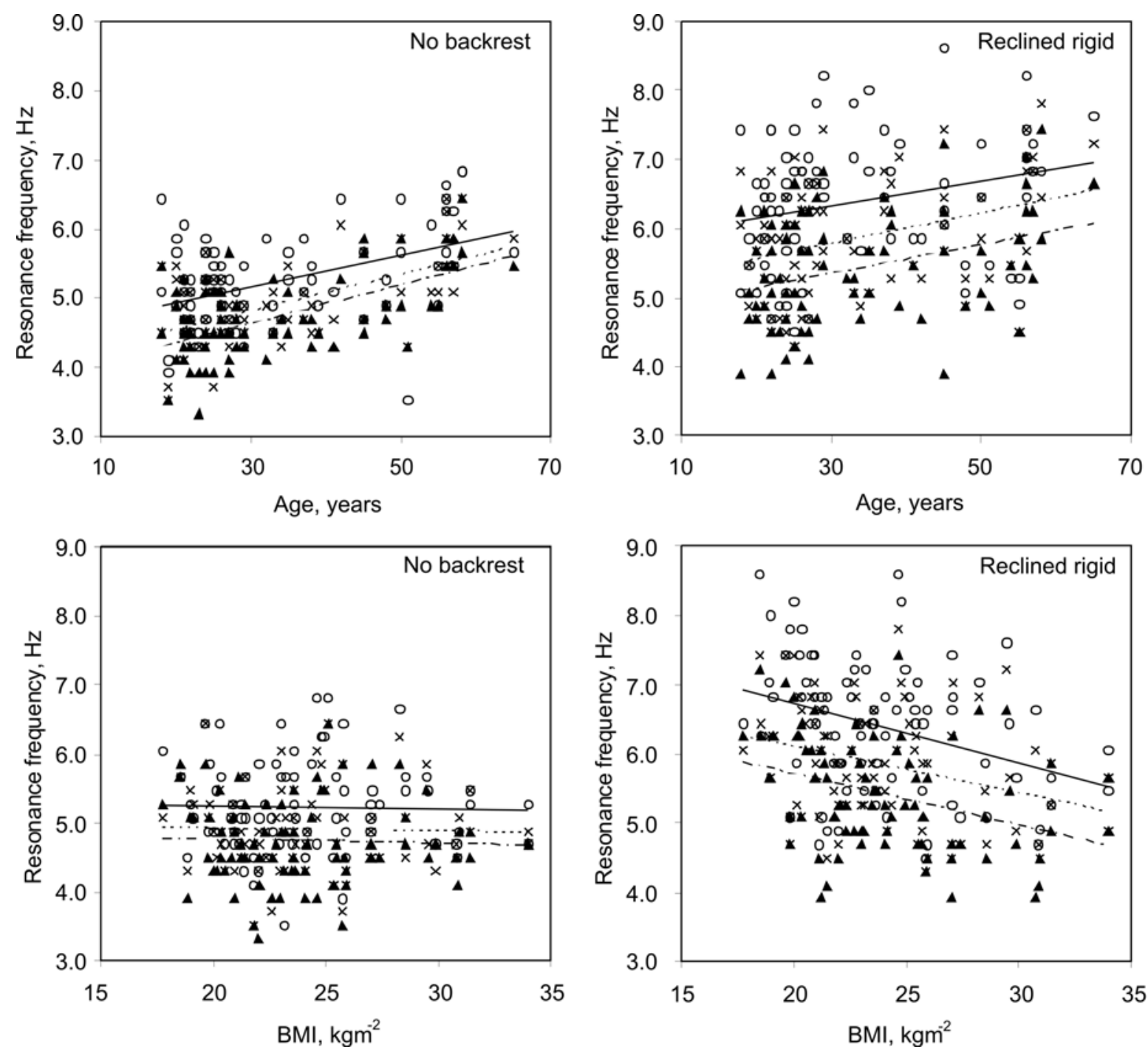

Figure 6 Effect of age and body mass index (BMI) on the resonance frequency of 80 adults at three magnitudes of vertical vibration excitation (no backrest and reclined rigid backrest): $0.5 \mathrm{~ms}^{-2}$ r.m.s. ( $\circ), 1.0 \mathrm{~ms}^{-2}$ r.m.s. $(\times)$ and $1.5 \mathrm{~ms}^{-2}$ r.m.s. ( $\Delta$ ). Bivariate regression trend lines are also shown: $0.5 \mathrm{~ms}^{-2}$ r.m.s. $(-), 1.0 \mathrm{~ms}^{-2}$ r.m.s. $(\cdots)$ ) and $1.5 \mathrm{~ms}^{-2}$ r.m.s. $(\cdot-\cdot-)$. 

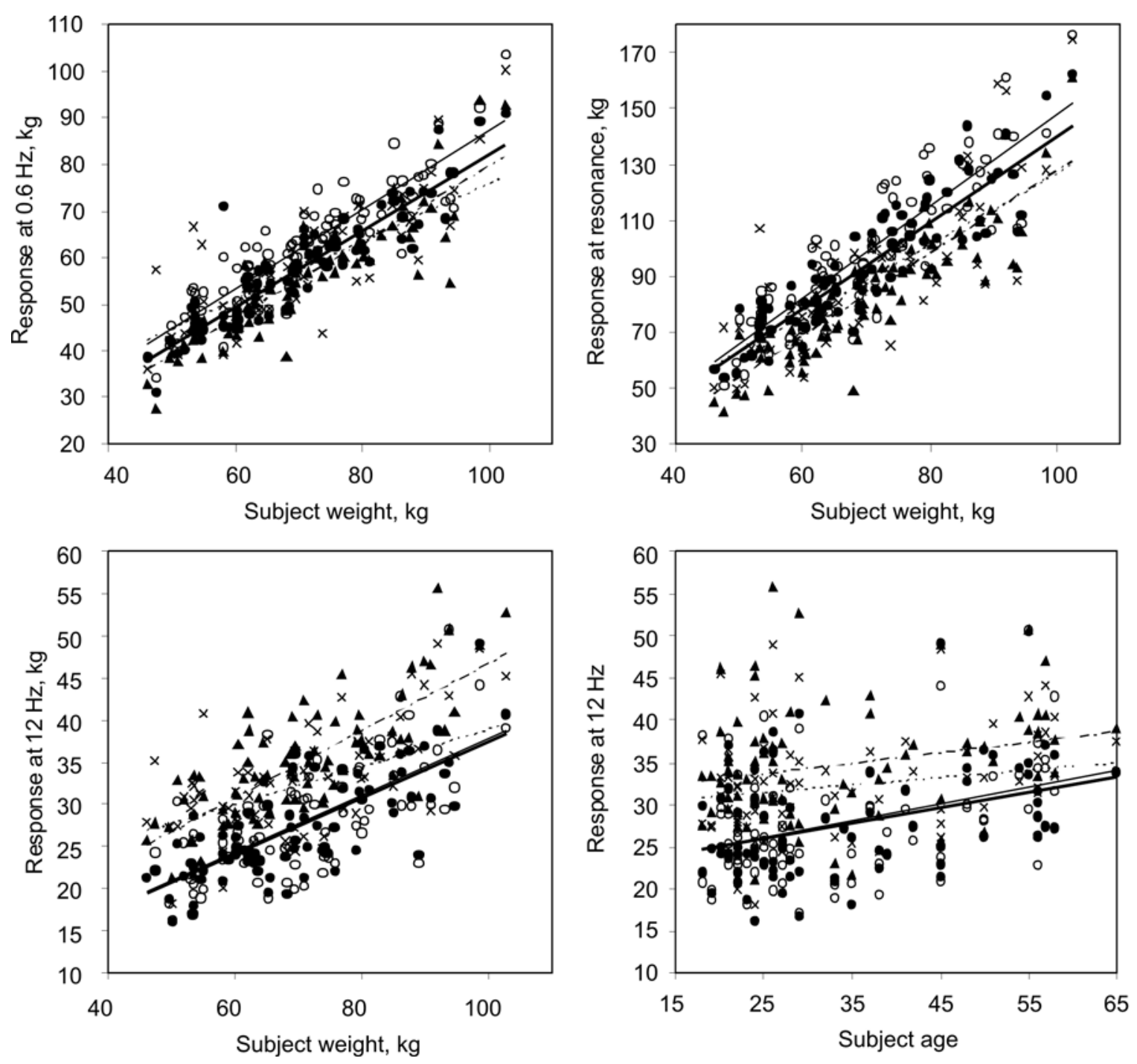

Figure 7 Effect of weight and age on the apparent masses of 80 adults at $0.6 \mathrm{~Hz}$, at resonance and at $12 \mathrm{~Hz}$ with four different backrest conditions $\left(1.0 \mathrm{~ms}^{-2}\right.$ r.m.s. excitation): no backrest $(\circ)$, upright rigid $(x)$, reclined rigid $(\Delta)$ and reclined foam $(\bullet)$. Bivariate regression trend lines are also shown: no backrest $(-)$, upright rigid $(\cdots)$ ), reclined rigid $(-)$ and reclined foam $(-)$. 